University of Wollongong

Research Online

Australian Institute for Innovative Materials -

Papers

Australian Institute for Innovative Materials

2013

Studying inhomogeneity of organic coatings using wire beam

multielectrode and physicomechanical testing

Sina S. Jamali

University of Wollongong, ssj198@uowmail.edu.au

D J. Mills

University of Northampton

Follow this and additional works at: https://ro.uow.edu.au/aiimpapers

Part of the Engineering Commons, and the Physical Sciences and Mathematics Commons

Research Online is the open access institutional repository for the University of Wollongong. For further information contact the UOW Library: research-pubs@uow.edu.au 


\title{
Studying inhomogeneity of organic coatings using wire beam multielectrode and physicomechanical testing
}

\begin{abstract}
The effect of thickness, curing temperature and solvent on the structural inhomogeneity of several types of organic coatings has been investigated. The local distribution of electrochemical resistance was studied using a wire beam multielectrode array, while the inhomogeneity at a larger scale was examined using $\sim 3 \mathrm{~cm} 2$ area detached coatings. Physicomechanical tests were also employed to address the structural changes occurring because of variation in curing temperature and the type (or absence) of solvent. Results acquired by wire beam electrode and from the detached coatings showed that increasing the thickness and curing temperature improves the homogeneity of the coating as does elimination of solvent. Waterborne coatings exhibited a relatively homogeneous low resistance with a resistance lower than the threshold required for effective corrosion protection. Results of physicomechanical examination suggest that unreacted functional groups and water absorption are of the main causes of formation of structural defects in organic coatings.
\end{abstract}

\section{Keywords}

beam, wire, physicomechanical, multielectrode, coatings, studying, organic, inhomogeneity, testing

Disciplines

Engineering | Physical Sciences and Mathematics

\section{Publication Details}

Jamali, S. S. \& Mills, D. J. (2013). Studying inhomogeneity of organic coatings using wire beam multielectrode and physicomechanical testing. Corrosion Engineering Science and Technology, 48 (7), 489-495. 


\title{
Studying inhomogeneity of organic coatings using wire beam multi-electrode and physico-mechanical testing
}

\author{
Sina S. Jamali ${ }^{1}$, Douglas J. Mills ${ }^{*}$ \\ School of Science and Technology, \\ University of Northampton, \\ St George's Avenue, \\ Northampton, NN2 6JD, \\ UK
}

Tel $00441604893005 / 3213$

E-mail douglas.mills@Northampton.ac.uk

\footnotetext{
${ }^{1}$ Current address:

Intelligent Polymer Research Institute

Innovation Campus, University of Wollongong

Wollongong, NSW 2522

Australia
}

Tel 0061426736630

E-mail sina.jamali198@uow.edu.au 


\section{Abstract}

Effect of thickness, curing temperature and solvent on the structural inhomogeneity of several types of organic coatings has been investigated. The local distribution of electrochemical resistance was studied using a wire beam multi-electrode array while the inhomogeneity at a larger scale was examined using approx. $3 \mathrm{~cm}^{2}$ area detached coatings. Physico-mechanical tests were also employed to address the structural changes occurring because of variation in curing temperature and the type (or absence) of solvent. Results acquired by wire beam electrode and from the detached coatings work showed that increasing the thickness and curing temperature improves the homogeneity of the coating as does elimination of solvent. Waterborne coatings exhibited a relatively homogeneous low resistance with a resistance lower than the threshold required for effective corrosion protection. Results of physico-mechanical examination suggest that unreacted functional groups and water absorption are of the main causes of formation of structural defects in organic coatings.

Keywords: Organic coating, inhomogeneity, ionic conduction, wire beam multi-electrode, conduction mechanism

\section{Introduction}

Early studies of Bacon, Smith and Rugg, ${ }^{1}$ revealed the significance of ionic conduction for corrosion resistance properties of an organic coating. It was observed that a coating that maintained a resistance of $10^{8} \mathrm{Ohm} . \mathrm{cm}^{2}$ provided good corrosion protection while one whose resistance fell below $10^{6} \mathrm{Ohm} . \mathrm{cm}^{2}$ did not. If the resistance started high a subsequent sharp drop was found to be a precursor to coating failure. Increased ionic conduction through the organic coating was determined as the being the cause of the resistance fall and this diminished the protective properties of organic coating. ${ }^{2}$ Later studies of Mayne and Scantlebury, ${ }^{3,4}$ revealed that there are regional differences within a single coating with regards to the ion permeability and hardness. The small and isolated areas of relatively high permittivity were called $D$ types as the ionic conductivity directly followed that of the ionic strength of the electrolyte. The reverse was true in the remainder of the coating, classified as I type. ${ }^{5}$ It was later deduced that these highly permeable areas form only a small fraction of the coating. ${ }^{6}$ Further studies elucidated the great significance of coating inhomogeneity to the corrosion protection afforded by varnish coatings, with corrosion being initiated at the $\mathrm{D}$ areas. $^{7}$

Most of the early studies looking at variability in the resistance in organic coatings were conducted using $1 \mathrm{~cm}^{2}$ areas of film. Later work suggested that the much more permeable areas which cause $D$ type behaviour, occupy only a small fraction of a $1 \mathrm{~cm}^{2}$ film. To further study the distribution of resistance within a $D$ type coating, it was considered that a wire beam electrode (WBE), first introduced by Tan, ${ }^{8}$ would be ideal. This is a multi-piece electrode constructed with an array of metal wires embedded into an insulating material. The surface of each individual electrode serves as a small metal substrate. The principle of this type of electrode is based on subdividing a continuous area of a metal surface into many small parts and measuring the electrochemical properties of each part by means of individual isolated connections. A WBE has been successfully utilized for studying 
inhomogeneity and localized corrosion at surfaces such as steel, ${ }^{9,10}$ aluminium, ${ }^{11}$ and a range of organic coatings, ${ }^{12-16}$. Diameter of individual metal arrays varied between $127 \mu \mathrm{m}$ (made of gold) to $1.8 \mathrm{~mm}$ with a range metals (i.e. gold, aluminum, steel) used in construction of wire beam electrode. Tan, ${ }^{14,15}$ studied the effect of prolonged exposure to salt water on electrical homogeneity of organic coatings using a WBE. His results suggested a homogeneous electrochemical behaviour across the surface of each individual wire while the large statistical distribution of resistance revealed the presence of heterogeneity from wire to wire across the whole surface of the multi-electrode. More recent work by $\mathrm{Wu}$ et al., ${ }^{13}$ utilized a wire-beam electrode with 121 independent steel arrays to investigate the influence of thickness on variability in coating resistance applied to a steel surface. Their results revealed the significance of thickness on the homogeneity of paint and its ionic conduction. They also confirmed the early results of Mills and Mayne, ${ }^{7}$ in regards to the higher homogeneity of a double coat system compared to a single coat with the same overall thickness.

The aim of present study is to utilize a wire beam multi-electrode and compare it with the classic method of measuring $D / I$ ratio (normally expressed as \% $D$ type) for investigating the effect of coating thickness, curing temperature and presence/type of solvent. Physico-mechanical testing methods, DMTA and DSC, are used to address the structural changes of organic coatings in relation with to the change of inhomogeneity.

\section{Experimental}

\subsection{Material}

The alkyd varnish was based on a short oil soya based alkyd resin with $40 \% \mathrm{v} / \mathrm{v}$ solid content and xylene as solvent supplied by Pronto Industrial Paints Ltd. Solvent base and waterborne polyurethane (PU) coatings were acrylic polyol resins crosslinked with polyisocyanate. The solvent based and waterborne acrylics were SETALUX 1196 XX-60 and SETAQUA 6515, respectively, both supplied by Nuplex. Both poly-acrylic resins were crosslinked with Tolonate HDT-LV2, a low viscosity aliphatic polyisocyanate supplied by Perstorp. Stoichiometric mixing ratio of 1:1 of NCO:OH was used for the solvent base PU. A mixing ratio of 1.25:1 (excessive polyisocyanate) was used for waterborne PU to compensate for the NCO-water reaction. The epoxy paints (solvent based, waterborne and solvent free) were all commercial paints supplied by AkzoNobel International paints with $63 \% \mathrm{v} / \mathrm{v}$, $52 \% \mathrm{v} / \mathrm{v}$ and $100 \%$ solid contents, respectively. The mixing ratio recommended by AkzoNobel was followed.

\subsection{Methods}

In order to obtain the detached film, the liquid paint was applied on a non-stick PTFE (polytetrafluoroethylene) sheet (for alkyd coatings) or polypropylene sheet (for epoxy and PU coatings) using the spreader bar and carefully delaminated after it was fully dried. The coating thickness was then measured by a Defelsko PosiTest DFT thickness gauge. 
98 steel wires with $1.5 \mathrm{~mm}$ diameter were embedded in an acrylic mould to form a square array (Figure 1 left). The cross-section was carefully cut and polished using 240 grit emery to obtain a flat surface while each steel wire was left protruding at least $2 \mathrm{~cm}$ from the other side of the mould for further electrical connection and measurement. With 98 steel wires, each with $7.06 \mathrm{~mm}^{2}$ area, embedded in a $4 \times 4.5 \mathrm{~cm}\left(18 \mathrm{~cm}^{2}\right)$ area, the wires cross-section composed about $7 \mathrm{~cm}^{2}$ of the whole area. The coatings were then applied using a spreader bar. The same coatings were also applied with the same spreader bar to a steel panel for thickness measurement. The DC resistance of each coated wire was measured in $0.5 \mathrm{M} \mathrm{NaCl}$ solution using a $610 \mathrm{C}$ solid state Keithley electrometer against a calomel electrode (Figure 1 right). The multi-electrode was in solution for 24 hours before the DC measurement. All measurements were made at $\mathrm{RT}, 18-22^{\circ} \mathrm{C}$.

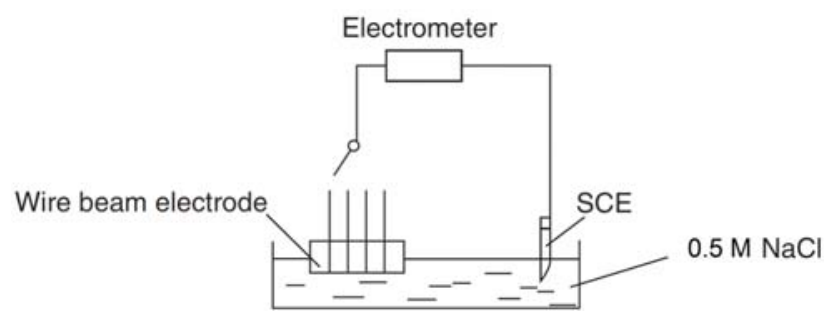

Figure 1 WBE configuration and measurement set-up

A distribution map of resistance was produced for each coating using the Microsoft Excel program. Values of individual wires were entered into a data sheet and the missing values (corresponded to the gap between wires) were estimated by averaging from the surrounding measured values. Subsequently the $13 \times 15$ matrix of values was plotted and both of the 3-D and lateral views were produced.

The $D / /$ ratio (expressed as $\% D$ type) was determined by measuring $D C$ resistance of $3.1 \mathrm{~cm}^{2}$ detached coatings using a $610 \mathrm{C}$ solid state Keithley electrometer. Detached films were cut into approx. $4 \mathrm{~cm}^{2}$ squares and mounted in $U$ shape glass cell (Figure 2 ) where the DC resistance could be measured in a two electrode arrangement across the coating using two calomel electrodes. The DC resistance was measured with $0.001 \mathrm{M} \mathrm{KCl}$ and $3.5 \mathrm{M} \mathrm{KCl}$ solutions to identify the conduction type of each piece. If the resistance was lower in the $3.5 \mathrm{M}$ solution than that in $0.001 \mathrm{M}$ solution it was classified as a $\mathrm{D}$ type. If resistance was higher in the $3.5 \mathrm{M}$ solution than that in the $0.001 \mathrm{M}$ solution it was classified as I type. Coatings were in contact with each solution for at least 2 hours before the measurements were made. All measurements were performed at room temperature, $18-22^{\circ} \mathrm{C}$. Subsequently \%D type was statistically calculated for 20 samples as the No. of $D$ types/No. of pieces of film examined. The different size of the exposed area used in this study $\left(3.1 \mathrm{~cm}^{2}\right)$ makes direct comparison with the Mayne results difficult. The $3.1 \mathrm{~cm}^{2}$ exposed area of each specimen will result in a higher $D$ to I ratio because of the greater chance of inclusion of a $D$ area in each specimen when compared with the Mayne method which examined $1 \mathrm{~cm}^{2}$ areas of film. 


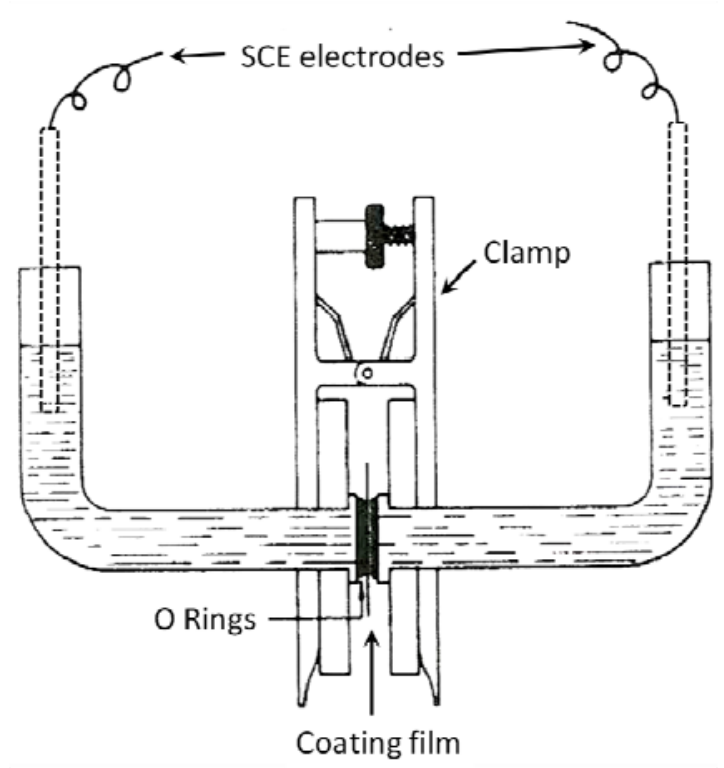

Figure 2 Experimental set-up for detached film measurements

Differential scanning calorimetry (DSC) measurements were performed with a METTLER TOLEDO DSC 821 at $5{ }^{\circ} \mathrm{C}$ heating rate. Standard $40 \mu \mathrm{L}$ crucible aluminium pans were used and the weight of samples was 8-12 mg. Samples were cut from fully cured detached films. All data presented here are normalized in regard to the weight of samples.

Dynamical thermo-mechanical analysis (DMTA) experiments were performed by a DMA Tritec 2000, Triton-technology at $5{ }^{\circ} \mathrm{C}$ min heating rate, $1 \mathrm{~Hz}$ oscillation under $1 \mathrm{~N}$ force and $20 \mu \mathrm{m}$ displacement. Storage and loss modulus were measured within the temperature range of 20 to $120^{\circ} \mathrm{C}$. Specimens were rectangular detached films with a fixed length of $11 \mathrm{~mm}$ and approximate width of $8 \mathrm{~mm}$ fixed to a single cantilever with tension mode. Tg was determined at the maximum of the $\alpha$ transition peak of the tan $\delta$.

\section{Results and discussion}

\subsection{Effect of thickness}

Figure 3 and 4 show the distribution map of DC resistance obtained using the WBE, across alkyd films with $18 \mu \mathrm{m}$ and $32 \mu \mathrm{m}$ thickness on steel. Resistance values have been converted to represent the resistance of each wire on an $\Omega \mathrm{cm}^{2}$ basis. Different shades of each colour (e.g. dark green to light green) appears to be an art effect used by MS Excel and may not represent a differentiation of values. Five categories of colours (cyan, purple, green, red and dark blue) have been assigned to represent different classes of DC resistance from high to low. The number of spots with low resistance (1E5 - 1E7) has been significantly decreased from 20 to 6 by increasing the thickness from $18 \mu \mathrm{m}$ and $32 \mu \mathrm{m}$. The immediate implication is that the electrochemical inhomogeneity is an inherent characteristic of polymer film and this becomes less pronounced as the film thickness increases. It is therefore reasonable to assume that the more permeable areas, i.e. D areas, are very 
small areas with remarkably different conduction properties to the rest of the film ${ }^{3}$. The statistical analysis (results not presented) showed that increasing the film thickness also narrowed down the distribution of resistance values. In other words, increasing thickness improved the electrochemical homogeneity of alkyd film. This is also supported by the results of \%D type presented in Figure 5 in a larger scale. The \%D type increased significantly by increasing the thickness of film from $75 \mu \mathrm{m}$ to $85 \mu \mathrm{m}$ and $110 \mu \mathrm{m}$. The presence of a highly conducting continuous aqueous pathway is the essential requirement for $D$ type behaviour. Thickening the polymer layer can potentially block or interrupt the conduction pathway by impermeable polymeric regions (e.g. regions of higher crosslinking density).

\section{$\mathrm{R} / \Omega \mathrm{cm}^{2}$}

Figure 3 DC resistance map acquired by WBE from alkyd coating on steel with $18 \mu \mathrm{m}$ of film thickness after 24 hours in $0.5 \mathrm{M} \mathrm{NaCl}$

$$
\mathrm{R} / \Omega \mathrm{cm}^{2}
$$

Figure 4 DC resistance map acquired by WBE from alkyd coating on steel with $32 \mu \mathrm{m}$ of film thickness after 24 hours in $0.5 \mathrm{M} \mathrm{NaCl}$

\subsection{Effect of curing temperature}


A comparison between the \%D type of detached pieces of the $85 \mu \mathrm{m}$ alkyd film cured at $60^{\circ} \mathrm{C}$ and at RT is made in Figure 5. The significantly lower D/l ratio of alkyd when cured at elevated temperature can be explained by two mechanisms. The first explanation is based on enhanced crosslinking as a result of higher temperature and higher yield of oxidative co-polymerisation reactions. The second is that it is the result of more efficient solvent evaporation at higher temperatures. Solvent pockets when entrapped inside the film may produce hollows and permeable areas. At higher temperature accelerated molecular motions increases the intermolecular space (or free volume) therefore the solvent can be removed more efficiently while the coating is not completely set.

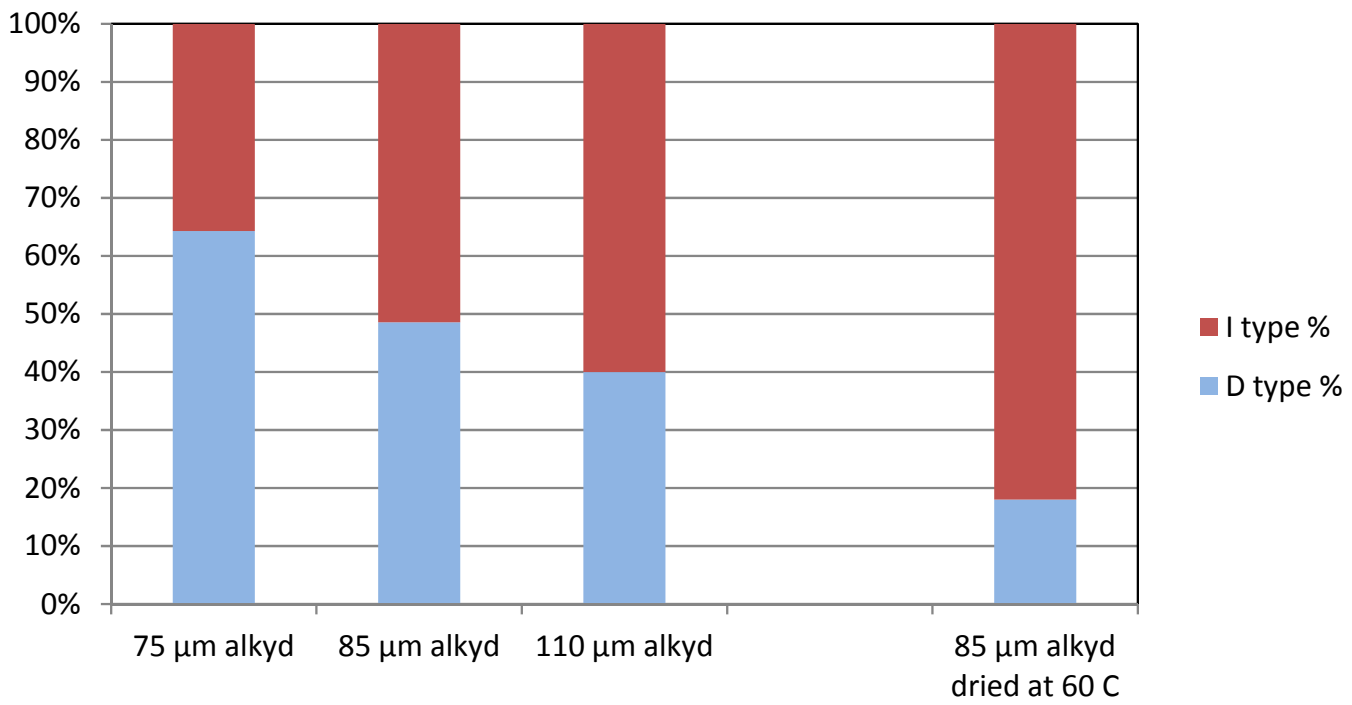

Figure $5 \%$ of D types of alkyd films cured at RT and $60{ }^{\circ} \mathrm{C}$ with $85 \pm 5 \mu \mathrm{m}$ film thickness (to obtain \% I types subtract interface value from 100)

Figure 6 illustrates the resistance map obtained using the WBE for an alkyd film applied on steel with $32 \mu \mathrm{m}$ film thickness which was force cured at $60^{\circ} \mathrm{C}$ for $24 \mathrm{hr}$. In comparison with Figure 4, force drying of the alkyd at $60^{\circ} \mathrm{C}$ has significantly decreased the number of low resistance spots compared to the sample cured at RT. Also statistical analysis shows a significant increase of the average resistance over the whole 98 wires as a result of force drying at $60^{\circ} \mathrm{C}$. 
Figure $6 \mathrm{DC}$ resistance map acquired by WBE from forced cured alkyd coating at $60^{\circ} \mathrm{C}$ for $24 \mathrm{hr}$ with $32 \mu \mathrm{m}$ of film thickness after $24 \mathrm{hrs}$ in $0.5 \mathrm{M} \mathrm{NaCl}$

DSC results, shown in Figure 7, reveal a significantly higher residual post-cure exothermic peak for the alkyd coating that was cured at RT compared with one cured at $60^{\circ} \mathrm{C}$. This result confirms that there are a larger number of unreacted functional groups when the alkyd is cured at room temperature and helps to explain the enhanced I type behaviour of the coating which was cured in the oven. Figure 8 shows DSC results of wet alkyd films in which the larger endothermic peak under $100^{\circ} \mathrm{C}$ is associated with the water removal from the film. DSC pans were pierced to let the moisture out. The result shows significantly higher water absorption by the RT dried coating compared to the force dried coating. Although the $\mathrm{C}=\mathrm{C}$ or unreacted alkyd functional groups are no different from $\mathrm{C}-\mathrm{C}$ groups in terms of hydrophilicity, the free space in the absence of cross-linked polymers provides larger space for water accumulation.

It should be noted that the presence of larger number of unreacted groups does not have a significant effect on the measured glass transition temperature, $T_{\mathrm{g}}$. This also has no significant effect on the storage modulus of alkyd as measured by DMTA. Figure 9 shows similar storage modulus for the wet alkyd coatings cured at RT and $60 \mathrm{C}$. Generally the lower storage modulus of wet films compared to dry film can be attributed to the presence of water in the film and its plasticizing effect. This plasticizing effect was shown clearer in Figure 10 as the first (and smaller) peak of $\tan \delta$ in the range of 20 to $25^{\circ} \mathrm{C}$. This peak, which was not observed for the dry film sample, is associated with the plasticizing effect of water within the polymeric structure which facilitates movement of polymeric chains and softens the film. ${ }^{17,18}$ The DMTA technique did not show adequate sensitivity to differentiate the structural change of alkyd films cured at different temperatures. 


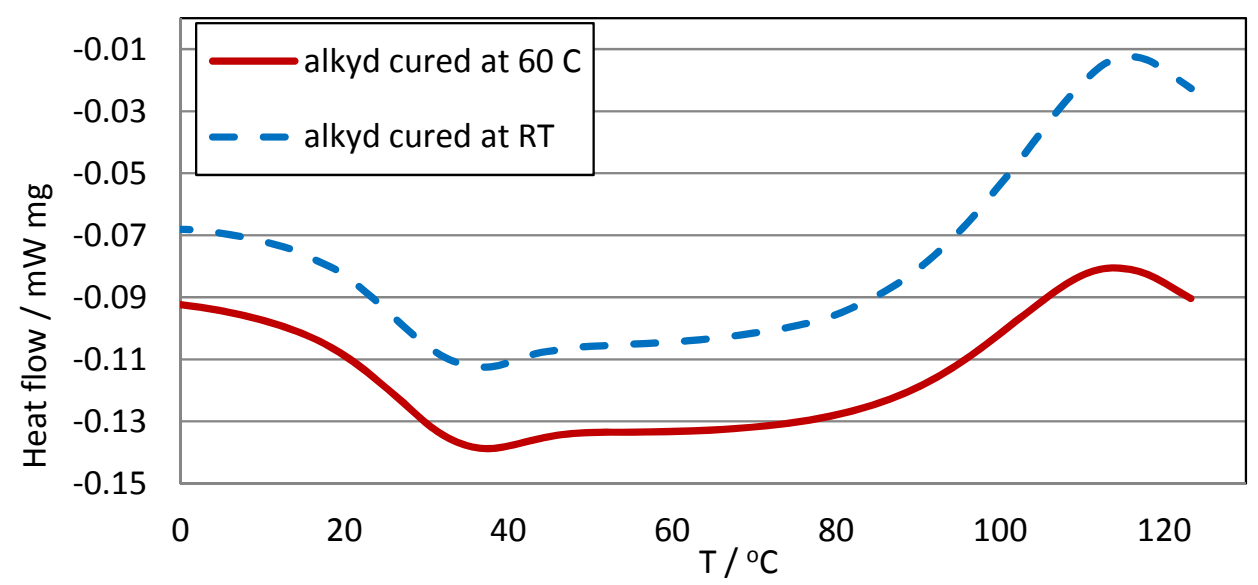

Figure 7 DSC thermograms of the alkyd coating cured at room temperature and at $60^{\circ} \mathrm{C}$

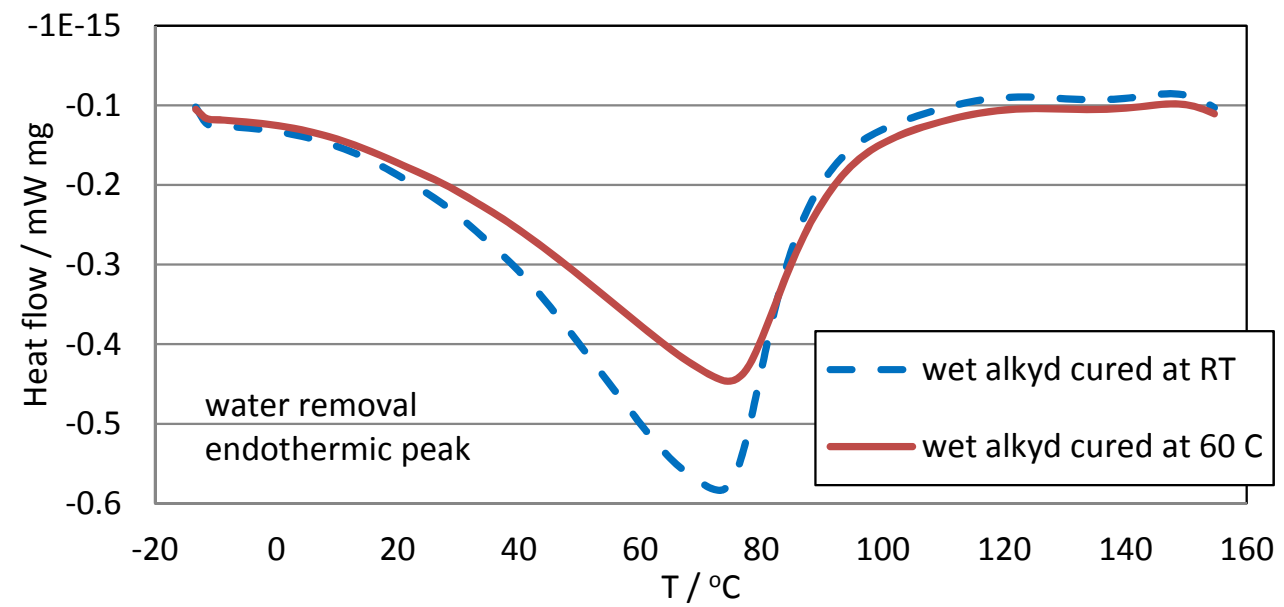

Figure $8 \mathrm{DSC}$ thermograms of the wet alkyd coating cured at room temperature and at $60^{\circ} \mathrm{C}$

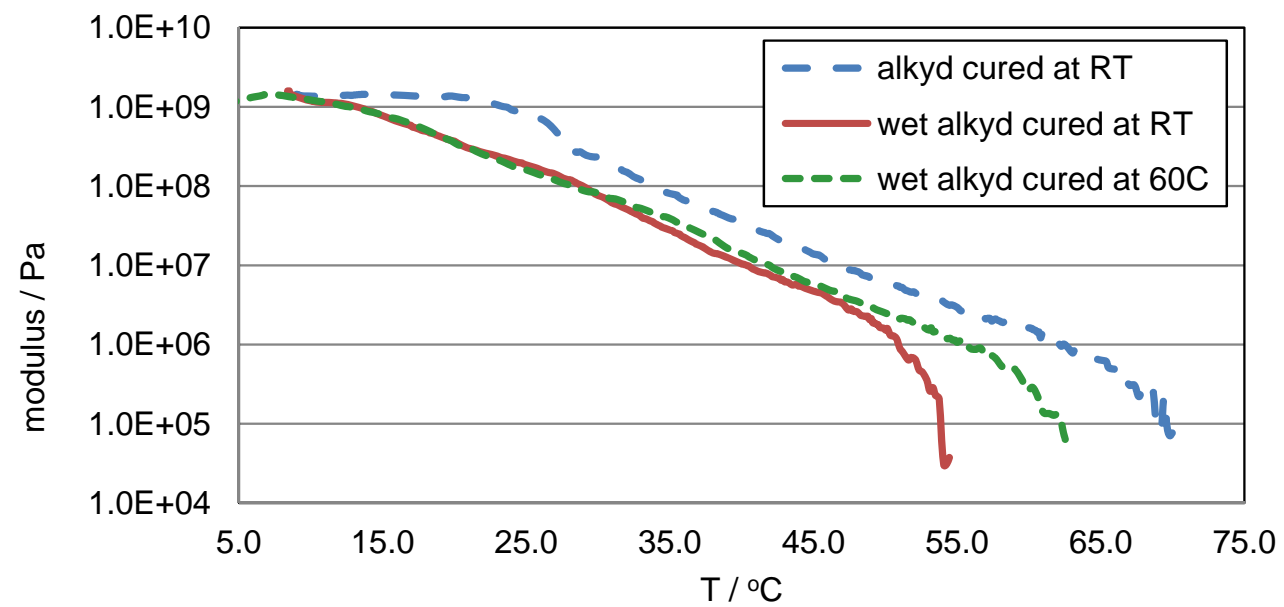

Figure 9 Storage modulus of dry and wet alkyd coating cured at RT and at $60^{\circ} \mathrm{C}$ measured by DMTA 


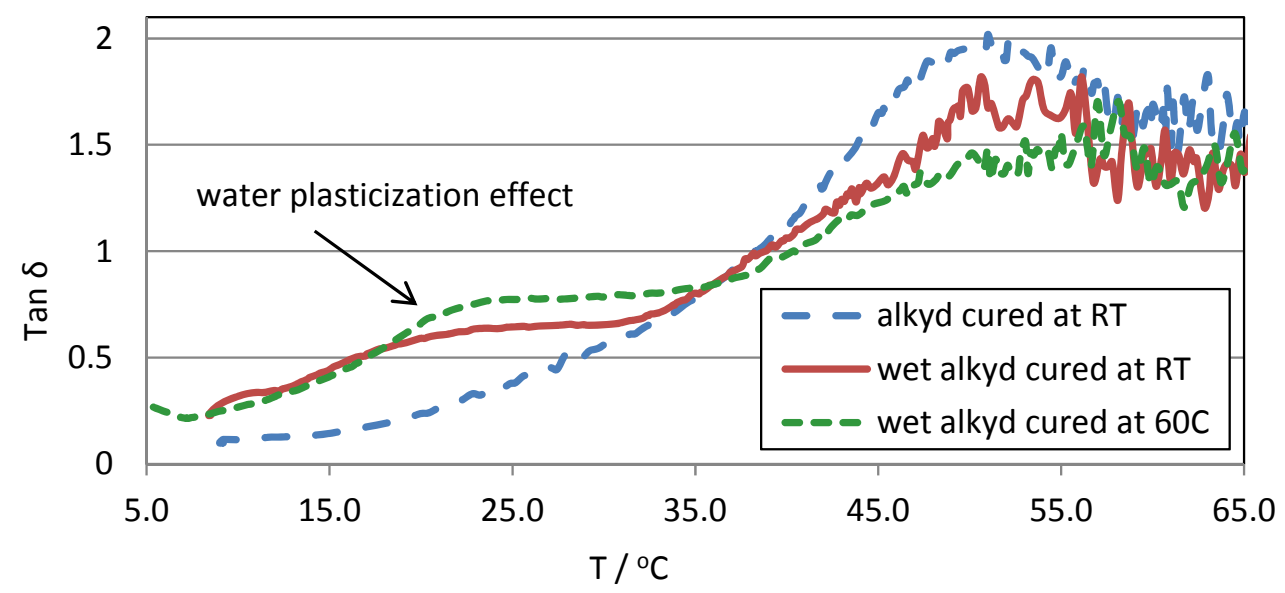

Figure 10 Tan $\delta$ of dry and wet alkyd coating cured at RT and at $60^{\circ} \mathrm{C}$ measured by DMTA

The beneficial effect of extended curing time on lowering the porosity of polyester coating and its permeability was also shown by Worsley et al., ${ }^{19}$. Post annealing of thermoset or crosslinked coatings after the coating was fully cured has been shown to make no significant difference to the homogeneity or $\mathrm{D} / \mathrm{l}$ type ratio of coatings. However a more recent study on a thermoplastic polycarbonate coating showed that post annealing can reduce the size and the number of pores and increase the homogeneity. ${ }^{20}$ The effect of temperature of cure was also investigated in a recent study using polyurethane varnish cured at $20^{\circ} \mathrm{C}, 70^{\circ} \mathrm{C}$ and $110^{\circ} \mathrm{C} .^{21}$ The results in that work revealed that elevated curing temperature up to $110{ }^{\circ} \mathrm{C}$ can improve $\mathrm{DC}$ resistance of coatings by about two orders of magnitude and this remained consistent for the duration of experiment. The improved performance of the coating was attributed to higher crosslinking density and uniformity of chemical structure as revealed by thermo-mechanical characterization.

\subsection{Effect of solvent}

The effect of solvent is studied by comparing detached pieces of a solvent free epoxy/polyamine paint $(65 \pm 5 \mu \mathrm{m})$, a waterborne epoxy/polyamine paint $(110 \pm 10 \mu \mathrm{m})$ and a solvent based epoxy/polyamine paint $(60 \pm 5 \mu \mathrm{m})$ and also a solvent base and waterborne PU varnish with $65 \pm 5 \mu \mathrm{m}$ and $85 \pm 5 \mu \mathrm{m}$ thickness respectively. The \% of D types are shown in Figure 11 . The immediate implication of the results is the uniformly low resistance (100\% D type behaviour) of waterborne coatings. The solvent base PU varnish had higher overall resistance (only $25 \% \mathrm{D}$ type) while the solvent base epoxy paint was $90 \% \mathrm{D}$ type. The solvent free epoxy paint stood in between with $57 \% \mathrm{D}$ type behaviour. 


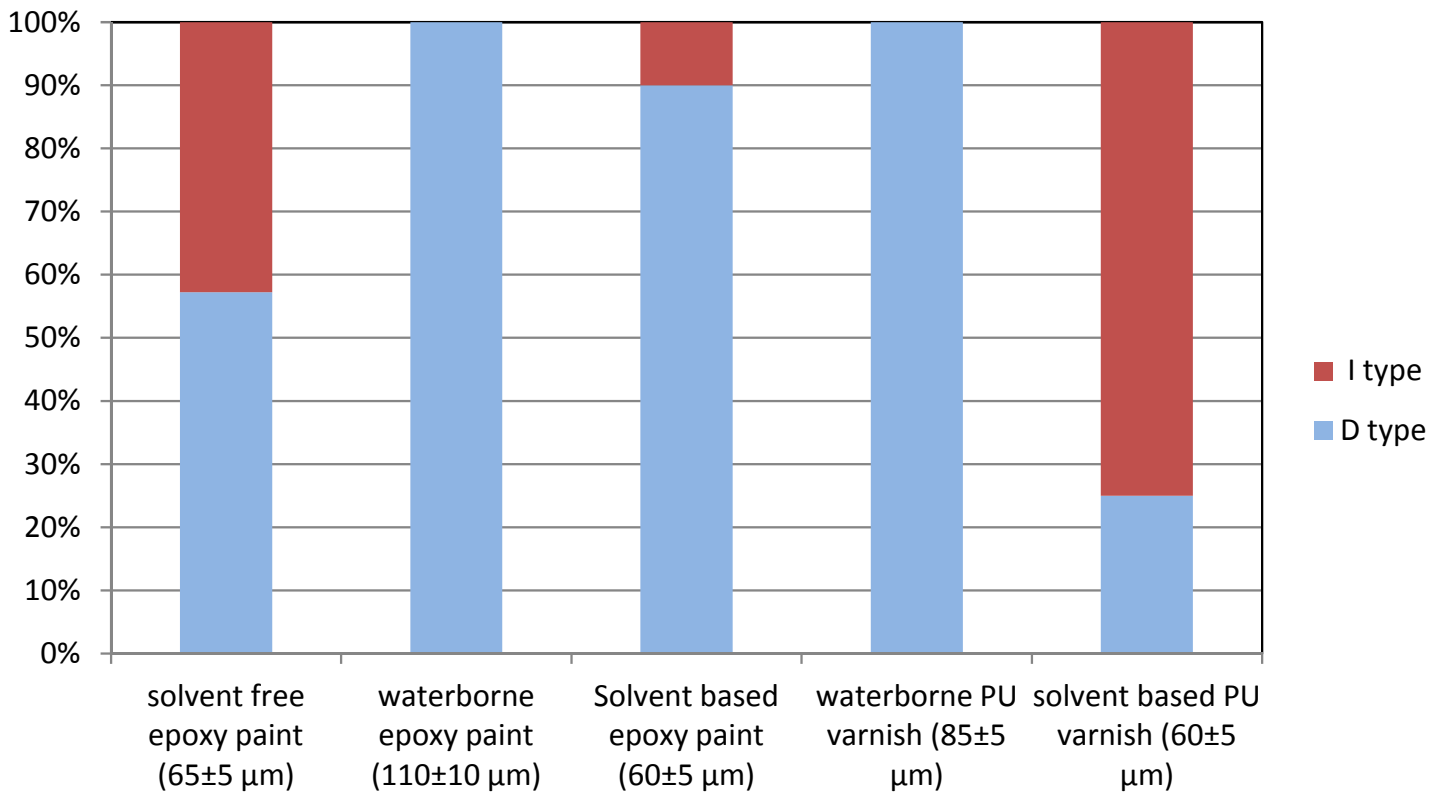

Figure $11 \%$ of $D$ types of epoxy/polyamine paint and polyurethane varnish coatings (to obtain \% I types subtract interface value from 100).

Solvents have always been suspected to play a part in making escape ways during the drying process which will later turn into highly permeable areas, i.e. D areas. ${ }^{22} 100 \%$ solid epoxies are normally made by using reactive diluents as viscosity modifiers. ${ }^{23}$ Reactive diluents tend to participate in crosslinking process and therefore will not contribute to formation of escape ways. On the other hand, waterborne resins are pre-polymerized polymer micelles with relatively narrow and uniform molecular weight distribution and have relatively homogeneous chemical structure. However, water-dispersible resins, such as waterborne epoxy and PU, are in general highly hydrophobic as a result of the presence of surface active agents (emulsifiers) in the film or a highly ionic structure of resin. ${ }^{24}$ The remarkably higher water absorption of waterborne epoxy paint is also confirmed by DSC results shown in Figure 12. Similar result was also achieved for PU varnishes (data not presented). The water sorption increases the polymer permittivity and molecular mobility as a result of the plasticizing effect. ${ }^{25}$ The highly hydrophilic resin in both cases of waterborne epoxy paint and waterborne PU varnish is believed to be the main reason for their $100 \% \mathrm{D}$ type behaviour. An earlier study by Mayne and Mills, ${ }^{7}$ also showed $100 \%$ D type behaviour of waterborne styrenebutyl acrylate paint with a uniform resistance distribution. The unsatisfactory level of protection afforded by waterborne epoxy paint on steel was also stated by the manufacturer (AKZO Nobel, International paints) which could be a result of the $100 \% \mathrm{D}$ type characteristic of the coating.

Mayne, $^{22}$ in his last contribution to this field, published in 1989, compared a solvent free epoxy/polyamine varnish $(80 \mu \mathrm{m})$ with a solvent based epoxy/polyamine varnish $(100 \mu \mathrm{m})$. His results revealed superior (100\% I type) behaviour of solvent free epoxy which was attributed to the absence of interference of solvent with the curing process thus achieving a highly homogeneous structure. It should be noted again that all works at the Mayne group were performed using $1 \mathrm{~cm}^{2}$ specimens while here $3.1 \mathrm{~cm}^{2}$ specimens are used and thus cannot be directly compared to Mayne's results. However the one case of exception is the $100 \%$ I type behaviour at which the size of 
specimen makes no difference. Compared to the earlier results of Mayne indicating 100\% I type behaviour of solvent free epoxy varnish, pigmentation seems to have negatively influenced the homogeneity of solvent free epoxy paint that was studied here. This could be as a result of void formation or poor interfacial interaction between pigment and resin. ${ }^{26}$

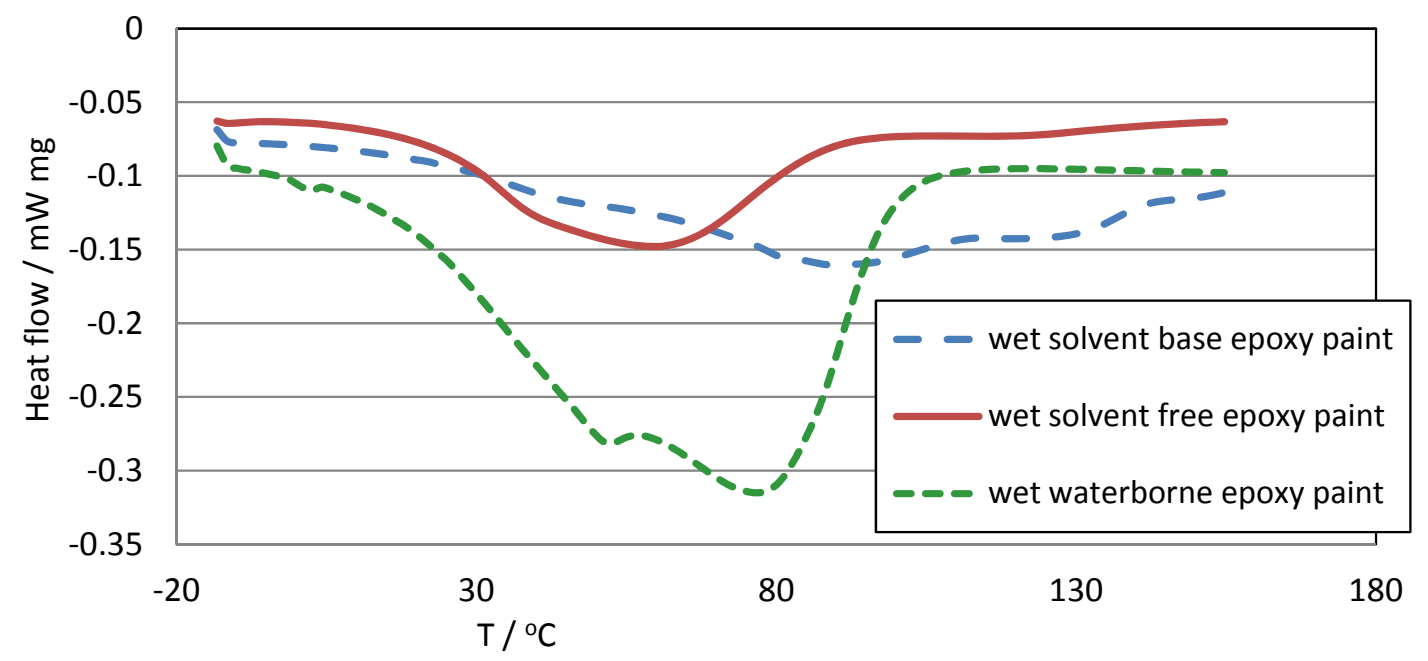

Figure 12 DCS thermograms of wet solvent base, waterborne and solvent free epoxy paints

Figures 13 and 14 show tan $\delta$ and storage modulus of wet films of solvent base, waterborne and solvent free epoxy paints. The water plasticization effect is observed on both solvent based and waterborne epoxies while the solvent free epoxy does not show such effect. Also an interesting observation is that the $\mathrm{Tg}$ of solvent free epoxy is lower than the $\mathrm{Tg}$ of solvent base and waterborne epoxies in water despite its better performance. The relationship between $\mathrm{Tg}$ and polymer permittivity has been addressed elsewhere. ${ }^{27,28}$ It appears that as long as the $\mathrm{Tg}$ of coating is higher than ambient temperature the permittivity is no longer influenced by thermal properties. However, a significant increase of free volume may increase permittivity and ionic conduction above Tg. A recent study by Li et al. also showed that the polarity of resin dominates the equilibrium water content while the free volume is the main factor for diffusion coefficient and activation energy of water sorption. ${ }^{29}$ 


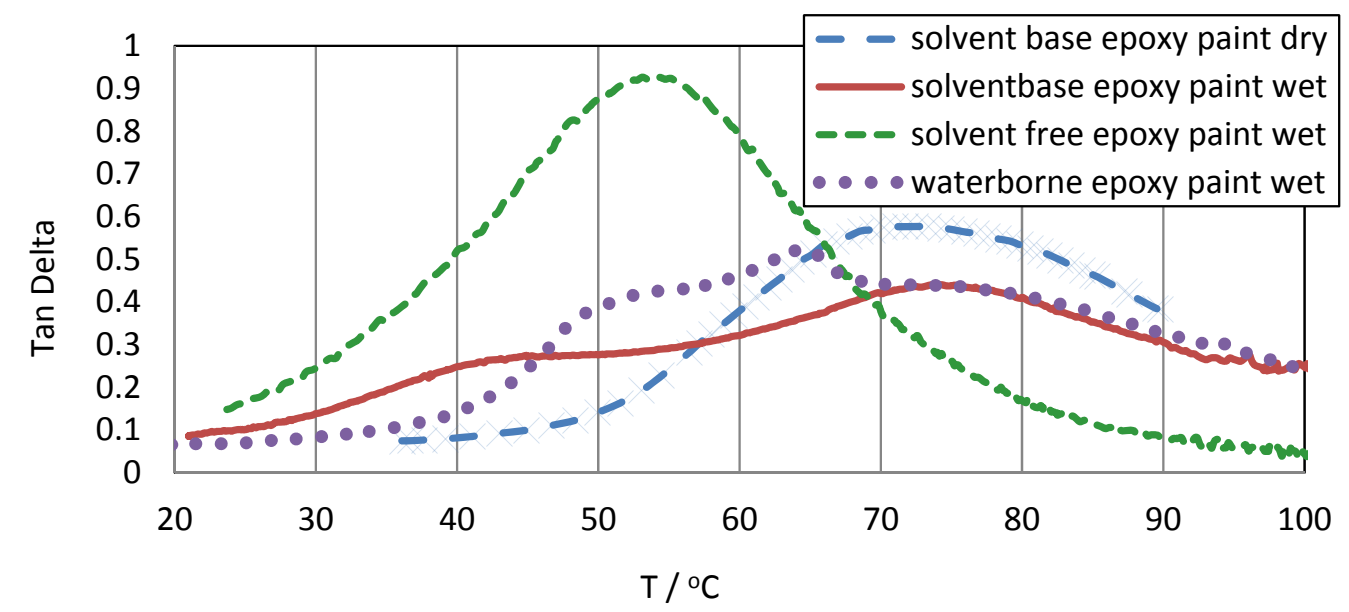

Figure 13 Tan $\delta$ of solvent base, waterborne and solvent free epoxy paints after being soaked in deionized water for $24 \mathrm{hrs}$

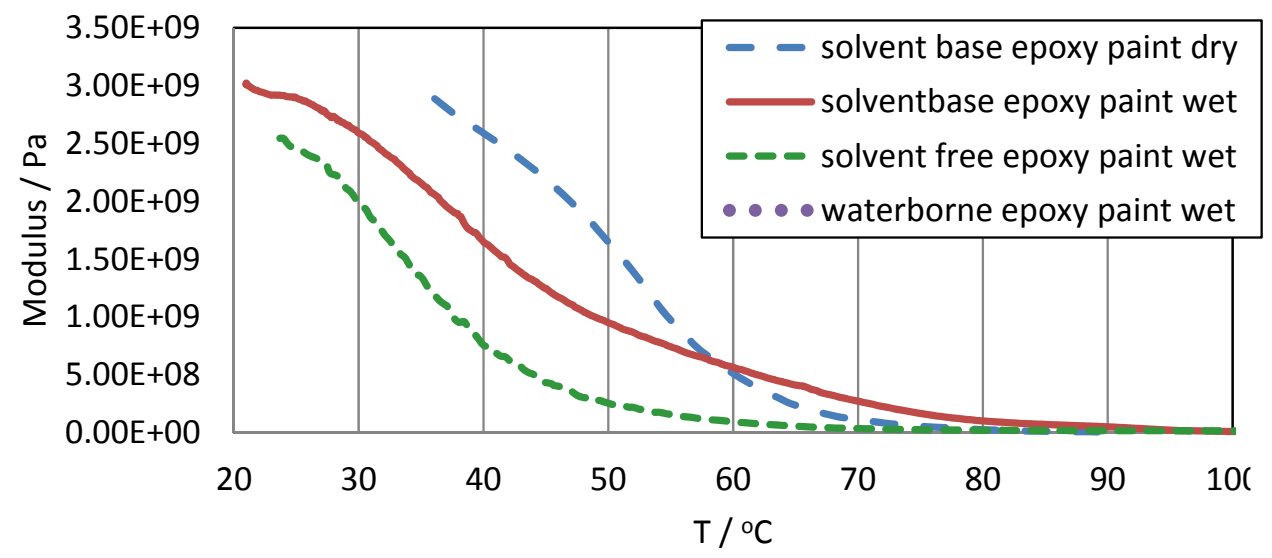

Figure 14 Storage modulus of solvent base, waterborne and solvent free epoxy pair soaked in deionized water for $24 \mathrm{hrs}$

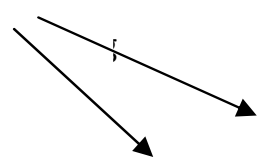

The inhomogeneity of waterborne polyurethane varnish on steel was further studied using the wire beam multi-electrode. The thickness of coating was $45 \mu \mathrm{m}$ and it was immersed in $0.5 \mathrm{M} \mathrm{NaCl}$ solution for $24 \mathrm{hr}$ before the measurement was made. Results showed a relatively homogeneous resistance across the electrode surface with around $82 \%$ of resistances in the range of $1 \times 10^{8}-2 \times 10^{8}$ $\Omega \mathrm{cm}^{2}$. But there were several areas with much lower resistance down to $2 \times 10^{6} \Omega . \mathrm{cm}^{2}$. The results are in-line with an earlier study on waterborne acrylic and vinylidene coatings. ${ }^{30}$ Compared to solvent based coatings, a generally lower resistance with less variation of value among nominally identical samples was reported for waterborne coatings. This was attributed to the local breakdown of waterborne coatings. The multi-electrode result presented in Figure 15 provides evidence for local breakdown of a low resistance waterborne coating as well as locating the breakdown areas. 
Figure 15 DC resistance map acquired by WBE coated by waterborne polyurethane varnish showing distribution of resistance on steel substrate. The film thickness was $45 \mu \mathrm{m}$ and the measurement was made after $24 \mathrm{hrs}$ in $5 \mathrm{M} \mathrm{NaCl}$

\section{Conclusion}

Multi-electrode results showed that increasing the thickness of an alkyd film increases both the resistance and the homogeneity of the film. The multi-electrode also detected the changes in homogeneity and average resistance as a result of the force drying at $60^{\circ} \mathrm{C}$. Similar results were achieved by measuring the $\mathrm{D} / \mathrm{I}$ type ratio of relatively large detached pieces of coating. It is therefore concluded that the Multi-electrode array method is a powerful way of finding out relatively quickly about the effect of important variables such as composition, drying conditions, thickness on the local resistance and homogeneity of coatings.

The increased I type behaviour achieved by increasing the thickness of coating can be explained by the higher chance of disconnection throughout the ionic pathway when the coating thickness is increased. Placement of an insulating phase (I type region) within the conducting pathway results in blockage and overall exhibition of I type behaviour.

In the case of the improved homogeneity achieved by elevated curing temperature, it is believed that more effective removal of solvent and enhanced crosslinking synergistically improved the coating. The DSC results indicated that the enhancement in resistance and in homogeneity brought about by force drying is associated with a higher yield of oxidative reactions and improved crosslinking at elevated temperature.

It is suggested that crosslinking deficiency of polymers such as epoxy and PU have a synergistic effect on coating permittivity and inhomogeneity by providing larger space between non-linked polymer chains and by providing larger number of unreacted hydrophilic groups such as $-\mathrm{NH},-\mathrm{OH},-$ NCO. This study also showed that waterborne coatings are intrinsically hydrophilic and may not afford anti-corrosion protection by barrier mechanism. The surface active agents used for emulsification and/or high ionic content of resin could remarkably increase the water uptake and 
results in $100 \%$ D type coatings. The waterborne PU coating exhibited $100 \% \mathrm{D}$ type behaviour with a uniform resistance distribution.

\section{Dedication to Prof. James David Scantlebury}

This paper is dedicated to the memory of David Scantlebury. David was known well by one of the authors (DJM) and admired very much by the other author (SSJ). It is thought that the content of this paper would be "up David's street" as he worked directly on homogeneity of anti-corrosive coatings in his PhD studies conducted in Dr Mayne's laboratory. Also the researches of many of his PhD students touched on this area. As well as being a brilliant teacher and very interesting and entertaining company, David was an inspiring research leader. The world is a diminished place by his passing. But we that are left are carrying on (we hope anyway) his good work in this "quite difficult to get to grips with" field.

\section{Acknowledgements}

The authors wish to thank Pronto Paints, AKZO Nobel/international Paints, Nuplex and Perstorp for provision of materials. SSJ is also grateful to the Institute for Creative Leather Technologies (ICLT) (head Rachel Garfoot) at the University of Northampton, for provision of lab space and physicomechanical testing facilities.

\section{References}

1. R. C. Bacon, J. J. Smith and F. M. Rugg: 'Electrolytic Resistance in Evaluating Protective Merit of Coatings on Metals', Ind. Eng. Chem., 1948, 40, 161-167.

2. J. E. O. Mayne: 'The mechanism of inhibition of the corrosion of iron and steel by means of paint', Off. Digest., 1952, 24, 127.

3. D. Greenfield and J. D. Scantlebury: 'The protective action of organic coatings on steel: a review', J. Corros. Sci. Eng., 2000, 3, paper 5.

4. J. E. O. Mayne and J. D. Scantlebury: 'Ionic conduction in polymer films II. inhomogeneus structure of varnish films', Br. Polym. J., 1970, 2, 240-243.

5. E. M. Kinsella and J. E. O. Mayne: 'Ionic conduction in polymer films I. influence of electrolyte on resistance', Br. Polym. J., 1969, 1, 173-176.

6. D. J. Mills and J. E. O. Mayne: 'The inhomogeneous nature of polymer films and its effect on resistance inhibition', Proc. 'Corrosion Control by Organic Coatings', Bethelehem, PA, USA, 1981, 12-17.

7. J. E. O. Mayne and D. J. Mills: 'The effect of the substrate on the electrical resistance of polymer films', J. Oil Colour Chem. Assoc., 1975, 58, 155-159.

8. Y. J. Tan: 'Monitoring localised corrosion processes and estimating localized corrosion rates using a wire beam electrode', Corrosion, 1998, 54, 403-413.

9. Y. J. Tan, S. Bailey and B. Kinsella: 'Mapping non-uniform corrosion using the wire beam electrode method. I. Multi-phase carbon dioxide corrosion', Corros. Sci., 2001, 43, 1905-1918.

10. Y. J. Tan, S. Bailey and B. Kinsella: 'Mapping non-uniform corrosion using the wire beam electrode method. III. Water-line corrosion', Corros. Sci., 2001, 43, 1931-1937. 
11. D. Battocchi, J. He, G. P. Bierwagen and D. E. Tallman: 'Emulation and study of the corrosion behavior of Al alloy 2024-T3 using a wire beam electrode (WBE) in conjunction with scanning vibrating electrode technique (SVET)', Corros. Sci., 2005, 47, 1165-1176.

12. Z. Qingdong: 'Potential variation of a temporarily protective oil coating before its degradation', Corros. Sci., 2001, 43, 317-324.

13. C. I. Wu, X. jun Zhou and Y. jun Tan: 'A study on the electrochemical inhomogeneity of organic coatings', Prog. Org. Coat., 1995, 25, 379-389.

14. Y. J. Tan: 'The effects of inhomogeneity in organic coatings on electrochemical measurements using a wire beam electrode: Part I', Prog. Org. Coat., 1991, 19, 89-94.

15. Y. J. Tan: 'The effects of inhomogeneity in organic coatings on electrochemical measurements using a wire beam electrode, Part II', Prog. Org. Coat., 1991, 19, 257-263.

16. Q. Zhong: 'Measuring corrosion beneath organic coatings using wire beam electrodes', in 'Techniques for Corrosion Monitoring', (ed. L. Yang), Ch. 4, 2012, USA, Woodhead Publishing Ltd.

18. G. P. Bierwagen, K. Allahar, B. Hinderliter, A. M. P. Simões, D. E. Tallman and S. G. Croll: 'Ionic liquid enhanced electrochemical characterization of organic coatings', Prog. Org. Coat., 2008, 63, 250-259.

19. G. P. Bierwagen: 'The physical chemistry of organic coatings revisited-viewing coatings as a materials scientist', J. Coat. Technol. Res., 2008, 5, 133-155.

20. D. Worsley, D. Williams and J. S. Ling: 'Mechanistic changes in cut-edge corrosion induced by variation of organic coating porosity', Corros. Sci., 2001, 43, 2335-2348.

21. G. S. Sekhon, S. Kumar, C. Kaur, N. K. Verma and S. K. Chakarvarti: 'Effect of thermal annealing on pore density, pore size and pore homogeneity of polycarbonate NTFs', Radiat. Meas., 2008, 43, 1357-1359.

22. W. Schlesing, M. Buhk and M. Osterhold: 'Dynamic mechanical analysis in coatings industry', Prog. Org. Coat., 2004, 49, 197-208.

23. J. E. O. Mayne: 'The crosslinking and adhesion to mild steel of epoxypolyamine films', in 'Advance in Corrosion Protection by Organic Coatings III', (eds. J. D. Scantlebury and M. W. Kendig), 1-7, 1989, Cambridge, UK, Electrochemical society.

24. P. K. T. Oldering: 'The chemistry of epoxy resins', in 'Waterborne and Solvent Based Epoxies and Their End User Applications', (ed. P. K. T. Oldering), 11-57, 1996, London, John Wiley \& Sons.

25. P. K. T. Oldering: 'The chemistry of epoxy resins', in 'Waterborne and Solvent Based Epoxies and Their End User Applications', (ed. P. K. T. Oldering), 126-131, 1996, London, John Wiley \& Sons.

26. S. Duval, Y. Camberlin, M. Glotin, M. Keddam, F. Ropital and H. Takenouti: 'Influence of the thermal transition on the evaluation on water-uptake in surface polymer film by EIS method', in 'New Trends in Electrochemical Impedance Spectroscopy (EIS) and Electrochemical Noise Analysis (ENA)', (eds. F. Mansfeld, F. Huet and O. R. Mattos), 50-59, 2001, Pennington, USA, The Electrochemical Society.

27. R. S. Fishman, D. A. Kurtze and G. P. Bierwagen: 'Pigment inhomogeneity and void formation in organic coatings', Prog. Org. Coat., 1993, 21, 387-403.

28. C. H. Hare: 'Free volume', J. Prot. Coat. Lin., 1996, January, 67-80.

29. C. H. Hare: 'Water Permeability in unpigmented films', J. Prot. Coat. Lin., 1997, September, 67-86.

30. L. Li, Y. Yu, Q. Wu, G. Zhan and S. Li: 'Effect of chemical structure on the water sorption of amine-cured epoxy resins', Corros. Sci., 2009, 51, 3000-3006.

31. D. J. Mills and S. J. Mabbutt: 'Inhomogeneities in organic coatings. a look at their importance to protection and at ways of detecting them', in 'Advances in Corrosion Protection by Organic Coatings III', (eds. I. Sekine, M. W. Kendig, D. Scantlebury and D.J. Mills), 89-100, 1997, Noda, Japan, Electrochemical society. 